\title{
The Achievements and Countermeasures of Rural Town Agriculture Products' Quality Inspection System Construction-Take Changzhou, Jiangsu as an Example
}

\author{
Jieqiong Wang ${ }^{1}$, Xi Tao ${ }^{2}$, Yunzhong Zhai ${ }^{1}$ \\ ${ }^{1}$ Changzhou Agricultural and Livestock Products Quality Supervision and Test Center, Changzhou, China \\ ${ }^{2}$ Changzhou Agricultural Accounting Service Center, Changzhou, China
}

Email address:

544094083@qq.com(Jieqiong Wang),510256748@qq.com (Xi Tao)

To cite this article:

Jieqiong Wang, Xi Tao, Yunzhong Zhai. The Achievements and Countermeasures of Rural Town Agriculture Products' Quality Inspection System Construction-Take Changzhou, Jiangsu as an Example. International Journal of Applied Agricultural Sciences. Vol. 4, No. 3, 2018, pp. 81-85. doi: 10.11648/j.ijaas.20180403.14

Received: June 20, 2018; Accepted: August 22, 2018; Published: September 27, 2018

\begin{abstract}
Changzhou Agriculture Committee has already achieved some results in rural town agriculture products' quality inspection through informatization means. Currently, 43 township (street) rapid detection stations in the city have been running efficiently for more than 5 years. The article elaborates on the key point of rural town agriculture products' quality test system construction in Changzhou, including team construction, construction of facility, environment, system, archives and construction of operating mechanism. It focuses on characteristics and highlights of inspection scope, equipment configuration and test data upload on the current township rapid detection work combined with information technology means. It also presents the existing problems and countermeasures to enhance development from now on.
\end{abstract}

Keywords: Agriculture Products, Quality Safe, Inspection and Testing, System Construction, Rural Town

\section{Introduction}

Currently, production and management of our country's agriculture production faces the situation of huge producers, weak sense of responsibilities and slack supervisions. According to $<$ The law of PRC on the safe quality of agriculture products $\rangle,<$ Opinions on the supervision and administration of safe quality of edible agricultural products from Ministry of Agriculture and General Bureau of Food and Drug Administration $>$ and $<$ Pilot work on the management of qualified certificate of edible agricultural products $>$, it is necessary to establish a management system of edible agricultural products adapted to the market access system, which can promote producers to adopt a series of quality control measures to ensure safe qualities with the assurance of qualified certificate. The most important means of issuing certification is to conduct detection. By means of quick test, it can regulate the operation of agriculture products, formulate an effective forcing mechanism, and implement the main responsibility of production, in order to establish a long-term supervision mechanism for the safe quality of agricultural products. Changzhou agriculture committee has since 2011 comprehensively promoted the construction of rural town agricultural products' rapid monitoring stations, which symbolizes effective explorations and practices in sampling, testing and data reporting. The stations fully implement mobile terminal sampling, and have made the data seamlessly connected to the supervision platform with the data uploaded to the regulatory platform, mobile supervision platform and grid platform in time. This measure has innovated the means of agricultural products supervision, and comprehensively improved the ability and level of safe quality supervision of agricultural products in Changzhou.

\section{Method}

The focus and achievements of rural town agricultural product quality inspection system.

\subsection{Mature Construction of Team, Condition and Operation Mechanism}

By the end of 2012, Changzhou has established rapid 
inspection stations for agricultural products with clear functions, proper personnel, matching power, normative profession and powerful service by means of strengthening construction and increasing investment. Meanwhile, Changzhou has formed a four-level inspection system in agriculture products taking the advantage of the municipal level detection center as the leader, the urban level monitoring station as the backbone, the town and the production testing room as the basis.

\subsubsection{Team Building}

The rural town fast testing stations in the whole city staff 93 people, including a total of 44 full-time inspection staff accounted for $47 \%$, permanent staff account for $73.1 \%$, college graduated and bachelor degree or above accounted for $94.6 \%$, senior titles accounted for $60 \%$, and people majored in agronomy accounted for $51.6 \%$. The stable and high quality team ensured the daily supervision and monitoring work laid a good foundation. Staff funds and daily operations are subject to full budget finance management.

\subsubsection{Construction of Facilities, Environment, Systems and Archives}

The city owns 43 township(streets) rapid test stations of agricultural products with moderate scale, reasonable layout and suitable structures and functions. The stations mainly have executive offices, sample preparation rooms, and test rooms, with some additions to file rooms and other auxiliary reagents warehouse. The constructions of external environment and internal environment standards are carried out in the same time, including installing the brand of rapid test stations in a prominent place outside the station house, setting up the test results bulletin boards and public opinion boxes, putting up signs on the room doors, requiring people work with certificates. The stations establish and improve the laboratory system, daily and test file management, and other internal management systems. The city's 43 rapid detection stations have all built comprehensive rapid detection stations for agricultural and livestock aquatic products with a total investment nearly 7 million yuan, of which 5.5 million yuan is invested in instruments and equipment, realizing 198 sets of rapid-test instruments for agricultural and livestock aquatic products in total, and 3.2 sets of rapid-test instruments for agricultural products and 2.7 sets of rapid-test instruments for livestock products available at each rapid test station on average.

\subsubsection{Operation Mechanism Construction}

The city's 43 townships (streets) rapid test stations are operating normally. Since May 2015, the city has pioneered the use of mobile terminals for sampling nationwide. By the end of June 2016, By the end of June 2016, there were nearly 7,000 sampling units, more than 13,000 samples and nearly 60,000 samples tested. The whole process from "sampling", "testing" to "data reporting" is documented and traceable, which ensures the effective operation of township inspection.

\subsection{Improvement of the Inspection Capabilities of Rural Agricultural Products Making Use of "Internet Plus"}

\subsubsection{Varieties of Test Samples Covered All Areas}

So far, the 43 township (street) rapid test stations mainly observe local agriculture and aquatic products production, test the sample of the species mainly local production of large consumption, which can represent the local agriculture and basic conditions. The total number of samples collected in each town is no less than 300 vegetables, 50 livestock \& poultry products and aquatic products, of which no less than 10 are livestock products. One thing to point out is that the annual sampling plan covers all vegetable enterprises and administrative villages. It is encouraged to use mobile terminal to sample as much as possible during sampling. Once a suspected positive sample is detected, it shall immediately report to the local agricultural products supervision department and take corresponding supervision measures. The suspected samples shall be sent to the qualified testing department for confirmation.

\subsubsection{High Configured Test Equipment More Convenient}

In 2016, Changzhou Agriculture Committee developed new pesticide residues quick test equipment and intelligent residual quick test equipment together with equipment companies, and equip every township (street) quick test stations with each one, according to the characteristics of the villages and towns rapid detection and operation situation of the last three years. The speedometer is equipped with wireless network transmission function. After sampling by mobile phone, the sample is downloaded to the speedometer in the testing task bar and uploaded to the monitoring platform directly after all tests are completed on the speedometer. The process is simple and highly operable, and the detection process is truly networked and real-time. The detection directly to the base makes work more convenient and efficient without computers.

\subsubsection{Strong Communication and Uploading of Test Data}

From 2015 to 2016, Changzhou government took out 10 million yuan in each year to fully implement a grid regulation of agriculture products, making a comprehensive survey on all producers, and established a four level grid supervision system of the safe quality of agriculture products covered the municipal, the urban, the township (street), and the executive village. The supervision to the extent of all people, all areas, and all process was hence realized by strengthening training evaluations. The results of informatization construction on agricultural products supervision are mainly reflected on the grid platform. In 2016, Changzhou Agriculture Committee upgraded the monitoring information management platform based on the original inspection module of the agricultural products supervision platform and mobile supervision platform. By establishing, management of project task, management of sampling information, management of test data, and management of statistical analysis, supervision efficiency of the agricultural product quality safety was hence increased by promoting informationization management. 
Through the application of the platform, routine test data of agricultural and livestock aquatic products collected by agricultural product quality and safety testing center(station), test data of agriculture production enterprises, test data from other provinces or cities who come to Changzhou to sample, are all made into the grid monitoring information management platform. Based on testing data collection, sorting, comprehensive analysis and results reporting, it is certain to realize connectivity of the municipal, the urban, and the township within the scope of city, to establish a monitoring network data sharing, standardize the sampling process and inspection process, etc., to realize detection to the traceability of agricultural products. By establishing the early warning model of test data and carrying out early warning work, Changzhou has provided reliable, timely and accurate supervision information for agricultural products supervision and better guarantee the quality and safety of agricultural products.

\subsection{Improvement of the Ability of Agricultural Products' Testing and Early Warning}

In general, Changzhou Agriculture Committee mainly focuses on the solid foundation of the whole inspection system. Relying on the municipal testing institutions, it strengthens the construction of the municipal agricultural product test system and constantly improves the ability of agricultural product testing and early warning.

\subsubsection{Complete and Strengthen Test Equipment}

Since 2015, Changzhou Agriculture Committee has started grass-roots agricultural products detection project, and has developed new intelligent agricultural residue velocity meter and animal residue velocity meter to realize mobile terminal sampling - sample testing - the whole process of data transmission in real time to upload, getting rid of the PC terminal. In the past two years, the city has made rapid tests of 67562 agriculture \& aquatic products samples, which proves the ability of flow detection and efficient detection has been greatly improved.

\subsubsection{Establish and Improve Test System}

In recent years, funds have been invested each year to improve the grassroots detection ability, and achieve the efficient operation of 43 township (street) agricultural rapid detection stations in the city. Basically, a "four-level" monitoring system has been formed, led by municipal detection centers, with municipal and district level detection stations as the backbone and based on the detection rooms of towns and production bases.

\subsubsection{Carry Out Test Process Tracing Mechanism}

Changzhou Agriculture Committee has Integrated platform and mobile supervision of agricultural product platform module resources, upgraded monitoring information management platform which includes all into the monitoring information management platform to all levels of quality safe of agricultural products inspection center (station) of routine testing data of aquatic products, agricultural products production traceability testing data of enterprises, provincial data sampling test of the provinces and cities to the city. Based on testing data, the platform collects, sorts, comprehensively analyses and reports, etc., to realize the city within the scope of city, county, township of connectivity, establish a monitoring network data sharing, standardize the sampling process and inspection process, realize the detection to the traceability of agricultural products. By establishing the early-warning model of detection data and carrying out the early-warning work, it can provide reliable, timely and accurate supervision information for the supervision of agricultural products and better guarantee the quality safe of agricultural products.

\section{Result}

The existing problems of rural town agricultural product quality inspection system.

\subsection{Unstable Inspection Teams}

According to statistics, the city's 41 villages and towns (street) rapid testing station monitoring personnel 96 people, including a total of 47 people full-time inspection staff, with an average of 2.3 in each station, and 1.4 full-time inspection staff. Supervision stations of agricultural products are new agencies, mostly hiring people from agriculture service stations who are responsible for agricultural products quality safe test. There are many ways of staffing, including compilation, secondment and employment. The staff is small and unstable, there is no special sampling car, the sampling cost is relatively high, and there is no work subsidy, hence working enthusiasm is affected to some extent. The instability of the whole inspection team has also affected the development of rapid detection work at the grass-roots level.

\subsection{Incomplete Tracing of the Process of Test}

\subsubsection{Incomplete Records of Sampling Information}

In 2015, Changzhou Agriculture Committee invited third-party evaluation units to evaluate the construction, operation and laboratory capacity of the 41 townships (streets) agricultural products rapid inspection stations in in the city. Through evaluation, it is found that the sampling information records are not complete, sampling which was not carried out through mobile phone terminals, did not register in time. Moreover, the sampling range is too concentrated and the coverage is not complete.

\subsubsection{Incomplete Original Data Records of Test}

Through investigation, it is found that all kinds of accounts and original records are filled not timely, incomplete and non-standard in the process of test. Some agricultural rapid test stations do not make original records, like equipment using records, maintenance records, sample disposal records are not made seriously, especially for the unqualified samples, original records do not keep for the re-inspection. 


\subsubsection{Incomplete Records of Data Processing}

Through consulting the books and the original records, it is found that the unqualified data were mainly caused by the unskilled operation of the equipment, the expired reagent and the unqualified inspection in practice. As there is no detailed classification records of unqualified data in the process of test and the unqualified causes, once the unqualified samples are found, the stations review and notify the farmers, but the re-inspection of the original record is not complete, not the whole process.

\subsection{Less Use of Test Results}

According to the current situation of township inspection, the qualified rate of data reported to the platform is more than $99 \%$, hence the role of rapid test stations has not been well played. It is time to change passive detection into active detection, not only to test samples listed for sale, but also to test aquatic products breeding, all kinds of vegetables in different periods irregularly. On the one hand, it can strengthen the propaganda guidance on how to correctly use at the grass-roots level, on the other hand it can also understand the status of drugs at different times, different crops, to carry on the risk assessment of pesticide residues, real play to the role of the rapid detection, improve regulatory advantage, from the source to ensure the safe quality of agricultural products.

\section{Discussion}

Suggestions on strengthening inspection of rural agricultural products.

Township rapid test is the key to improve the safety supervision of agricultural products quality. To ensure rapid test of villages and towns work into effect, we should strengthen the following aspects.

\subsection{Adhere to Publicity and Promotion; Improve the Initiative of Grass-Roots Test}

It is required to attach great importance on thought, publicity, grass-roots staff to fully realize the agricultural product quality safety overall responsibility of local government, the agricultural sector supervision responsibility, agricultural producers as the first responsible persons. Especially under the current situation of institutional reform, commercial food safety is supervised by Food \& Drug Administration, agricultural products before entering the market, including before entering the wholesale market, retail market, is managed by the department of agriculture. In 2015, the central file no. $1<$ Several Opinions on the intensify reform and innovation to speed up the construction of agricultural modernization $>$ made the clear requirement to strengthen the construction of township agricultural product quality and food safety regulatory capacity, to strict management of agricultural inputs, vigorously promote the standardization of agricultural production. Governments and departments at all levels must also attach great importance on the quality safe of agricultural products, comprehensively strengthen the standardization and accuracy of rapid test, making agricultural products test related to planning and policy of reference, and to provide a strong backing of food safety.

\subsection{Strengthen the Internal System; Give Full Play to Its Multi-Functional Role}

In order to promote the development of rapid detection in towns and villages, it is necessary to play its multi-function role on the existing basis.

\subsubsection{Play the Role of Training}

It is necessary to strengthen training and assessment on the test skills and laboratory management capacities of inspectors from rural supervision stations, and establish a sound personnel training, assessment and mobility mechanism. By conducting technical grand meeting, assessment on a regular basis, checking out the unqualified samples, and other forms, it is sure to motivate work initiative and enthusiasm, stable staff team, further make township agricultural regulatory achieve certain results.

\subsubsection{Play the Role of the Internet}

Changzhou Agriculture Committee has been at the forefront of agricultural product supervision by means of information technology. In rapid detection of agricultural products, it is vital to give full play to the role of the Internet, continue to ensure record and traceability of sampling, and shall not modify any testing data, further standardize the operation of the testing process, accurately and timely reflect the actual situation of grassroots detection.

\subsubsection{Play the Role of Mobile Test}

Currently, village inspectors test an agricultural product for less than half an hour from sample processing to printing results. Moreover, desktop computer is not required during sampling and test, mobile phone is more suitable for flow to the base, the enterprise to carry out the field detection, improve the efficiency of regulators to work at the grass-roots level, mobile detection will be the inevitable trend of future development.

\subsubsection{Play the Role of Test Data}

In the process of quick test in rural towns, we should always pay attention to the change of the data, data for the qualified and unqualified data, and standardize processing procedure and complete records for suspected positive result. Through data analysis, we can further find out the use and production process of input products in the production process of enterprises, and provide guidance and technical services for agricultural production subjects. Meanwhile, we shall provide decision-making basis for governments at all levels and agricultural product regulatory authorities, and provide technical support for the next step of implementing the linkage between the management of reserve production area and the management of market access. 


\subsection{Consolidate the Nature of Public Welfare, Seek Financial Support}

So far, governments at all levels attach great importance to the quality safe of agricultural products and put it into the first place. But from the point of the actual situation of Changzhou township test, there are many difficulties, such as some villages and towns inspectors are part-time work, their enthusiasm is not high, no more sampling traffic tools, sampling subsidies cannot be issued. Since 2014, Changzhou Agriculture Committee has allocated two mobile terminals to each of the city's 41 townships (streets) and grass-roots supervisors, and all the terminals are purchased by the government. It is hoped that governments at all levels can consolidate the public welfare nature of quick test of agricultural products and form a stable financial input channel We will give full play to the policy-oriented role of ensuring better quality safe of agricultural products.

\section{Conclusion}

This paper mainly introduces the key points of rapid inspection of rural agricultural products in Changzhou, including team construction, facilities, environment, system, file construction and operation mechanism construction. In the process of operation, "Internet $+"$ is used to improve the inspection service capacity of rural agricultural products, so as to cover a wide range of testing varieties, high configuration and convenience of testing equipment, test data interconnection and communication. Through years of operation, some problems have been gradually discovered, such as: the testing team is not stable enough; Incomplete traceability of the whole test process; the function of test results has not been fully played. In order to better carry out the inspection of rural agricultural products, it is suggested to increase publicity and promotion and improve the initiative of grass-roots inspection. Strengthen the internal system construction to better play the multi-function role; We will strengthen the nature of public welfare, strive for financial and financial support, better enhance the inspection capacity at the grassroots level, and steadily improve the quality and safety of agricultural products.

\section{References}

[1] Xiaohua Chen, <The situation and task of China's agricultural product quality safe supervision in 2013>, Quality safe of agricultural products, 2013(1):5-9

[2] Xiaohua Chen, <The ministry of agriculture's target and important measures to maintain "tongue safety" in 2014>, Quality safe of agricultural products, 2014(4):3-7

[3] Bin Luo, <Current situation and prospect of quality safe of agricultural products in China>, Quality safe of agricultural products, 2014(4):3-6

[4] Peixin Han, <Strategic analysis of the rapid development of green food in China $>$, Quality safe of agricultural products, 2016(3):7-11

[5] Yanhong Mao, < Economic law governing of the quality safe of agricultural products $>$, Law and society, 2010(1):109-110

[6] Wanqiong Wang, <Study on China's food safety regulatory system $>$, Journal of Southwest Agriculture University, 2011(2):14-18

[7] Guangde Liu, $<$ Analysis and countermeasures of quality safe of agricultural products in Chongqing $>$, Environment and development of Agriculture, 2013(1):23-25

[8] Zhichun Li, <Thoughts on quality and safety control of agricultural products $>$, Quality safe of agriculture products, 2013(1):18-19

[9] Nan Cheng, <Investigation and consideration on quality safe supervision of primary agricultural products>, Quality safe of agriculture products, 2015(1):12-14

[10] Honghua Chen, < Comparative study on domestic and foreign agricultural products traceability system $>$, Modern marketing, 2007(21):5-6 